\title{
SURREALISMO E FILOSOFIA: UMA NOVA HISTÓRIA A SER CONTADA.
}

\begin{abstract}
Augusto de Guimaraens Cavalcanti é doutorando no progrma de Diversidades Culturais, no Departamento de Ciências Políticas da PUC-Rio.
\end{abstract}

Email: veludoazul2@hotmail.com

\section{RESUMO:}

O objetivo deste artigo é expor o diálogo entre filosofia e literatura, tendo como fio condutor o surrealismo, construto que busca constantemente se atualizar através de novas leituras filosófico-literárias a serem praticadas. De modo a conceber um lugar dialógico reinventor de tradições, procuraremos interpretar o surrealismo não apenas como uma prática literária, mas também como uma forma de visão de mundo, "uma atitude do espírito humano", que é como o abordava o filósofo mexicano Octavio Paz. Ainda segundo declarou o mesmo Octavio Paz em discurso na ONU (logo antes de ganhar o Prêmio Nobel em 1990), "o século XX será conhecido não como o século do marxismo, mas como o século do surrealismo." (Paz apud Piva, 2009, p.156).

\begin{abstract}
:
The main objective of this article is to expose the dialogue between philosophy and literature, having as conductor the surrealism, construct that seeks to constantly update itself through new philosophicalliterary readings to be practiced. In order to conceive a dialogic place reinvented by traditions, we interpret the surrealism not just as a literary practice but also as a form of a world view, "an attitude of the human spirit," which is like dealing with the concept created by the mexican philosopher Octavio Paz. According to stated the same Octavio Paz in speech at UN (shortly before winning the Nobel Prize in 1990), "the 20th century will be known as the century of Marxism, but as the century of surrealism." (Paz apud Piva, 2009, p.156).
\end{abstract}

Muito pouco ou quase nada se tem escrito ou comentado no Brasil sobre o diálogo entre filosofia e literatura, tendo como fio condutor o surrealismo, construto que busca constantemente se atualizar através de novas leituras filosófico-literárias a serem praticadas. De modo a conceber um lugar dialógico reinventor de tradições, procuraremos interpretar o surrealismo não apenas como uma prática literária, mas também como uma forma de visão de mundo, "uma atitude do espírito humano", que é como o abordava o filósofo mexicano Octavio Paz. Ainda, segundo declarou o mesmo Octavio Paz em discurso na ONU (logo antes de ganhar o Prêmio Nobel em 1990), "o século XX será conhecido não como o século do marxismo, mas como o século do surrealismo" (Paz apud Piva, 2009, p.156).

Em leitura pioneira, de 1929, Walter Benjamin (1987, p.22) escreveu sobre o surrealismo de modo pioneiro, descrevendo-o não apenas como um "movimento programático", mas sim como uma expressão "poética", uma "usina artística geradora". Através do surrealismo, "uma formulação mais concisa e dialética", o domínio da literatura foi "explodido de dentro, na medida em que um grupo homogêneo de homens 
levou a 'vida literária' até os limites extremos do possível" (p. 32). Assim, os surrealistas são narrados como "intérpretes de sinais" que realizam suas iluminações simbólicas através de uma espécie de "dialética da embriaguez". Nestas "iluminações", o eu lírico romântico seria dissolvido pela poética onírica do processo pelo qual o sonho mina a individualidade. Como uma via oca, o espírito romântico não seria capaz de acolher o ato "anárquico" surrealista e seu pressuposto dialético de mistério, já que os românticos possuiriam uma concepção fanática e "estreita da essência da embriaguez". Como afirma Benjamin, não havia na Europa um conceito radical de liberdade desde Bakunin, mas os surrealistas disporiam desse conceito. Para Benjamin (1987, p.25), Breton realizou uma "surpreendente descoberta": "Foi o primeiro a ter pressentido as energias revolucionárias que transparecem no "antiquado", nos objetos que começam a extinguir-se, (...) nos locais mundanos, quando a moda começa a abandoná-los". ${ }^{\text {. }}$

Criado com nome proveniente de um poema de Guillerme Appolinaire, o surrealismo se inicia como expressão coletiva através de viagem inicática percorrida a pé por André Breton, Louis Aragon, Max Morise e Roger Vitrac, a partir de Blois, "cidade escolhida à sorte no mapa". Produto da escrita automática entre André Breton e Philipe Soupalt, Le champs magnetics (1920) é a primeira obra surrealista, construída por meio de prospecções e extrações psicológicas de seus dois autores. Já no Primeiro Manifesto (1924) André Breton (2001) propunha que o principal objeto surrealista seria a condição humana. Como expõe Breton:

Na medida em que o surrealismo nunca deixou de se reclamar de Lautréamont, de Rimbaud, é claro que o verdadeiro objecto do seu tormento é a condição humana, para além da condição social dos indivíduos. (...) Goya era já surrealista, assim como Dante, ou Ucello, ou Lautréamont, ou Gaudi. Por séculos ainda, será surrealista em arte tudo o que, através de novas vias, visará a uma emancipação maior do espírito." (Breton, 2001, p.129-285)

Publicado em 1948 no Cahiers du Collège Philosophique, o artigo "Humanismo surrealista e existencialista", de Ferdinand Alquié, assinala a existência de um "humanismo surrealista", idealizado como uma forma de libertar o homem pela poesia e reagrupar conceitos que a noção ocidental de progresso iluminista teria separado, como, por exemplo: razão e emoção, vida e arte, natureza e cultura, primitivo e moderno, profano e sagrado, real e sonho. Assim, Alquié aponta a necessidade de se pensar um "humanismo surrealista" contra certas interpretações realizadas pela cultura "clássica":

"Declarar que a razão é a essência do homem significa já cortá-lo em dois, coisa que a tradição clássica nunca deixou de fazer, ao separar no homem o que é a razão, e por isso mesmo verdadeiramente humano, daquilo que o não é, ou seja, instintos e sentimentos, assim considerados humanamente indignos" (Alquié apud Breton, 1994, p.110).

Após nomeação de Alquié, o termo "humanismo surrealista" foi adotado por Breton (1994) como forma de afirmar sua busca por uma "nova declaração dos direitos do homem". Leitura parecida possui Ernesto Sábato, ao afirmar que o surrealismo, para 
além das puras preocupações estéticas, possui uma atitude ante a vida que busca discutir a condição humana em busca de um "homem profundo". Segundo Sábato (1982, p. 88), "há algo no surrealismo que continua mantendo sua validade e que, de certa forma, se prolonga e se aprofunda no movimento existencialista: a convicção de que acabou o domínio da mera literatura e da mera arte". Segundo leitura de Diego Martinez Torron, entre todos os autores de expressão castelhana - espanhóis ou não - foi Octavio Paz o autor que mais profundamente assimilou o espírito dos surrealistas, tendo tido contato direto com André Breton. Paz, dessa forma, expõe suas influências surrealistas:

Fui surrealista em um momento de minha vida; procuro não ser infiel a esse momento... (....) A influência do surrealismo foi decisiva para mim, principalmente como atitude. Eu gosto muito do Benjamin Péret, que segue sendo aos meus olhos um exemplo moral, um exemplo de atitude de um verdadeiro poeta ante a vida. Achei no surrealismo a idéia de rebelião, a idéia do amor e da liberdade em relação com o homem..." (tradução minha). (Paz, 1980, p. 17-23)

Em um contínuo transcender-se, o surrealismo representa para Octavio Paz (1980) uma atitude do espírito humano face a métodos que não são gratuitamente estéticos. Intrinsecamente ligado a sua experiência, o artista surrealista procura sua obra no mundo, se apropriando da vida para além de suas questões teóricas. $O$ artista surrealista é o intelectual no mundo a viver sua vida como obra de arte, a experimentar sua vida como lugar de experimentação para sua obra: um artista experimental interligado com sua vida experimental. Assim, a intransigência do belo é defendida pelos surrealistas contra a noção de beleza grega, contra a transcendência do estético e pela dessacralização da obra de arte. Para os surrealistas somente a partir da cultura poderia o espírito humano ocidental se emancipar dos exclusivismos literários, sem concessões, já que para Breton, “toda beleza será convulsiva ou não será.” (Breton, 1994, p.125).

Dessa forma, Octavio Paz (1980). ressalta que desde o princípio a concepção surrealista "não distingue entre conhecimento poético da realidade e sua transformação". Assim, para a prática surrealista, "conhecer" deveria ser um ato transformador daquilo que se conhece; a atividade poética deveria voltar a ser uma “operação mágica." Em busca de uma "verdadeira vida", os surrealistas não partem de "uma teoria da realidade" ou de uma "doutrina de liberdade", mas sim de um "exercício concreto de liberdade" que visa "colocar em ação a livre disposição do homem em um corpo a corpo com o real" (p. 32).

Em sua prática, a poética surrealista busca transformar a arte em um empreendimento de ligação direta com a vida, como se pode notar no elogio feito por André Breton a Alfred Jarry, no Primeiro Manifesto Surrealista, pelo fato do diretor de teatro Jarry ter vivido sua vida como uma obra de arte. Nesse sentido, por exemplo, Breton (2001, p. 41) afirma que: "Rimbaud é surrealista em seu modo de vida".

Para colocar a poesia no centro da sociedade, o "humanismo surrealista" quer repovoar o mundo descartiano despovoado de deuses, de modo a reconciliar 
"pensamento e ação, desejo e fruto, palavra e coisa." (Paz, 1980, p. 38-39). Contra a descontinuidade entre obra e autor, o surrealismo busca construir uma atitude diante da vida de reencantamento; atitude esta que, ao negar ser uma metafísica da poesia ou uma técnica literária, procura se afirmar como um novo modo de sensibilidade do homem moderno, reencantado pelo domínio do poético.

Como propõe Breton (2001), nenhuma manifestação artística buscaria tão radicalmente interligar vida e arte em seu discurso quanto o surrealismo. Enquanto normalmente a vida do artista pode ser diferenciada do objeto artístico, na obra surrealista estas fronteiras muitas vezes se fundem e até se confundem muitas vezes. Segundo Breton (2001), a "linguagem foi dada ao homem para que dela use surrealisticamente" (p. 48), e assim adquira uma nova capacidade de sentidos através de uma "consciência poética dos objetos". Dessa forma, o surrealismo é um exercício por ele mesmo ruidoso, feito de diálogos e debates com a tradição. Em sua prática, a poética surrealista visa "restituir a linguagem à sua verdadeira vida"; de maneira a "remontar num salto ao nascimento do significante", e "esclarecer os símbolos até então imersos em trevas" (Breton, 2001, p. 357-358). O sentido máximo da operação surrealista seria tocar com as mãos o composto alquímico da linguagem, como Breton descreve:

Hoje em dia é um fato consabido que o surrealismo, enquanto movimento organizado, nasceu numa operação de grande envergadura que tinha por objeto a linguagem. (...) Tratava-se de que então? De nada menos que redescobrir o segredo de uma linguagem cujos elementos deixassem de se comportar como restos de naufrágio à flor das águas de um mar morto. (...) $\mathrm{O}$ ato decisivo do surrealismo foi manifestar-lhe o desenrolar continuo. A experiência mostrou que nelas figuravam muito poucos neologismos e que não se verificava nem desmembramento sintático nem desintegração do vocabulário. (...) $\mathrm{O}$ essencial, para o surrealismo, foi convencer-se de que havia tocado com as mãos a 'matéria-prima' (no sentido alquímico) da linguagem (...) A atitude do surrealismo em relação à natureza é governada, antes de tudo, pela concepção de 'imagem' poética que ele formulou inicialmente." (Breton, 2001, p. 355-360).

Segundo aponta Mário Pedrosa (2000), o surrealismo teria "tocado todas as claves da ação humana”. Como relata, Pedrosa conheceu os surrealistas Breton, René Magritte, Paul Éluard, Man Ray, Louis Aragon, Benjamin Péret e outros, nas cercanias da Place Blanche, em 1928, tendo colaborado com verbete do livro L'Art magique (1958), organizado por André Breton. Um ano depois da morte de Breton, Mário Pedrosa escreve o artigo "Surrealismo ontem, supra-realidade hoje", publicado no Correio da Manhã, em 27 de agosto de 1967, no qual assim descreve o surrealista francês:

Um dos homens realmente importantes de nosso tempo, que foi odiado e amado, ridicularizado também (causa aparente: alguns tiques de autocomplacência de uma personalidade de fato soberana) - refiro-me a André Breton - a quem Jean Paulhan (antes seu adversário que amigo) chamou de "herói intelectual do Ocidente" (...) O surrealismo quis sempre ser a poesia e a revolta em estado permanente. A Arte para ele era apenas um meio, como outro, de modificar o homem (...) Um dos pecados que para os surrealistas não tinha perdão era fazer a apologia do sonho como terreno de evasão 
ou apelos à vida sobrenatural, expressão de uma vontade puramente platônica senão mera desistência. (Correio da Manhã, em 27 de agosto de 1967).

Como interpreta Walter Benjamin (1987), este seu artigo escrito em 1929, pode ser compreendido como uma forma de crítica aos eruditos que até aquele determinado momento eram incapazes de determinar as "origens autênticas" do "movimento", e limitavam-se "a dizer que a respeitável opinião pública está sendo mais uma vez mistificada por um clique de literatos" (p. 27). Segundo Benjamin (1987), o surrealismo é extra-literário por origem e possui um paralelo de busca existencial, já que desde o ínicio André Breton teria declarado sua vontade de romper com uma prática que entrega ao público os precipitados literários de uma certa forma de existência, sem revelar essa forma. Para o filósofo alemão, o espírito romântico não seria capaz de acolher todos os pressupostos dialéticos de mistério surrealista:

Toda investigação séria dos dons e fenômenos ocultos, surrealistas e fantasmagóricos, precisa ter um pressuposto dialético que o espírito romântico não pode aceitar. De nada nos serve a tentativa patética, ou fanática de apontar no enigmático o seu lado enigmático; só devassamos o mistério na medida em que o encontramos no cotidiano, graças a uma ótica dialética que vê o cotidiano como impenetrável e o impenetrável como cotidiano. (...) Os surrealistas dispõem desse conceito. Foram os primeiros a liquidar o fossilizado ideal de liberdade dos moralistas e humanistas, porque sabem que a liberdade, que só pode ser adquirida neste mundo com mil sacrifícios, quer ser desfrutada, enquanto dure, em toda a sua plenitude e sem qualquer cálculo programático: É a prova, a seu ver, de que a causa da libertação da humanidade, em sua forma revolucionária mais simples (que é, no entanto, e por isso mesmo, a libertação mais total), é a única pela qual vale a pena lutar. (Benjamin, 1987, p. 32-33).

Seguindo o raciocínio de Benjamin (1987), as obras surrealistas não lidam com a literatura, mas com outra coisa - manifestação, palavra, documento, bluff, falsificação, e por isso mesmo devem ser compreendidas nestes termos intertextuais. Assim define Benjamin a importância da "aventura surrealista" e suas experimentações iniciadas nos anos 20: "Seria o momento de pensar numa obra que como nenhuma outra iluminaria a crise artística, da qual nós somos testemunhas" (p. 35). Atrelados no "conceito humanista de liberdade", as obras são consideradas experiências que estão em jogo, não teorias, e "muito menos fantasmas", e por isso mesmo, na leitura benjaminiana, o surrealismo pode ser descrito como uma "revolta amarga e apaixonada", engendrada por inspirações tanto antropológicas quanto filosófico-existenciais.

Nesse sentido, segundo Anna Balakian (1970), a convergência entre a crise da linguagem e uma busca existencial torna o surrealismo uma manifestação artística coletiva única na história da literatura, de um grupo que vislumbrou um diálogo entre filosofia e literatura em sua escrita:

What makes surrealism unique in the history of literature is that there is in its credo a convergence of the crisis of language with a revision of the notion of spirituality itself. (...) Thus, both Freud and Hegel proved to be influences in the most salutary sense of the word: they pointed a direction but raised an objection strong enough to lead to 
subsequent originality on the part of their disciples. As can be observed by examining these two influences, one of the basic characteristics of the surrealist mind is its uncompromising will to find a foolproof unity in the universe. Trough contingency with Freud and Hegel the surrealists were able to outgrow their initial nihilism and advance a credo of hope, based on faith in the potential capacity of the human mind for synthesis, synthesis of the human and material reality. In both philosophical outlooks, so contradictory on the surface, the surrealists found ground for the fundamental support they were seeking, reassurance for their monistic philosophy. (...) Considered in this light, surrealism was a twentieth-century integration of art and philosophy. Believing their efforts to run parallel to those of the modern scientists, they have tried to give proof that the arts are not behind the sciences in man's progress toward knowledge. Theirs was a gallant endeavor to surmount the superficial absurdity of life. We shall note in what follows, their concrete achievements in literary language and pictorial representation. (Balakian, 1970, p. 19-139)

Como expõe Octavio Paz (1984), a poética surrealista propõe um novo humanismo que visa restaurar a totalidade humana através de uma intervenção "sobre a própria matéria da linguagem, obrigando as palavras a entregar a sua vida secreta e revelar o misterioso comércio que mantêm para além do seu sentido" (Paz, 1994, p. 112). No composto alquímico da colagem, a imagem surrealista é essencialmente arbitrária, já que o alvo de sua linguagem é conciliar opostos. Em poemas compostos pela colisão de palavras raras, elementos plásticos são justapostos através de duas realidades aparentemente não conciliáveis, como por exemplo o "encontro fortuito de um guarda-chuva com uma máquina de costura em uma mesa de dissecação.” Ao empregar tal método imagético de tensionamento como técnica de suas colagens, "o máximo de precisão, para o máximo de desvario" (Paz, 1980, p. 15), o surrealismo recolhe as ruínas do dadá e prega a perda do lado fetichista de movimento artístico programático e escolástico para se concentrar na liberdade estética como motor contra seus próprios dogmas.

Nesta acepção, Antoigne Compagnon (1996) afirma que são os surrealistas que através de suas colagens são responsáveis por problematizar a relação entre o mundo e sua representação. Em um universo de montagens e colagens a unidade estilística do surrealismo está em sua incorporação teórico-discursiva de outros meios que não só o literário. Ao trabalhar a imaginação poética sobre o fazer manual artístico do artesão, o trabalho mental da invenção poética surrealista atua no transbordamento de seus meios, e por isso mesmo é intertextual por definição.

Julio Cortázar afirma que somente na França o surrealismo poderia ter surgido, como uma expressão fundada a partir da saturação do panorama filosófico do século XIX e reflexo da negação do sedentarismo positivista. Ao confrontar um tipo de literatura "esteticista" e uma "cultura livresca", o surrealismo constrói uma forma de equação entre o homem e o mundo, e antes de tudo, uma "concepção do universo", e não um "sistema verbal”. Dessa forma, Cortázar (1998, p.78) define: "Surrealista é o homem para quem certa realidade existe, e sua missão consiste em encontrá-la; nas pegadas de Rimbaud, não vê outro meio de atingir a suprarealidade senão a restituição, o reencontro com a inocência.". 
Através de uma atitude poética com a vida, André Breton (2001) defende a ideia do surrealismo como uma "fera renascente", um devir que "não corre qualquer sério risco de cessar enquanto o homem for capaz de distinguir um animal de uma chama ou de uma pedra". Assim, seria "tarde demais para que a semente do surrealismo" não germinasse ao "infinito no campo humano, juntamente com o medo e o mato, que deverão prevalecer sobre tudo o mais" (p. 159), posto que nas palavras de Breton (2001): "o surrealismo ainda se encontra no período dos preparativos e apresso-me em acrescentar que talvez este período dure tanto quanto eu." (p. 209).

Nesse sentido Octavio Paz (1980) descreve o quanto, em sua opinião, o surrealismo influenciou o século XX:

Hoje ninguém se atreve a negar que o surrealismo tem contribuído de maneira poderosa a formar a sensibilidade de nossa época. Além disso, essa sensibilidade, em boa parte, é criação sua. Porém a empresa surrealista não tem se limitado unicamente em expressar as tendências mais ocultas de nosso tempo e antecipar as vindouras; este movimento se propunha encarnar na história e transformar o mundo com as armas da imaginação e da poesia. (...) o surrealismo é um movimento de liberação total, não uma escola poética. Via de reconquista da linguagem inocente e renovação do pacto primordial, a poesia é a escritura da fundação do homem. O surrealismo é revolucionário porque é uma volta ao princípio do princípio. (...) A vontade surrealista de apagar as fronteiras entre arte e vida não é nova, são novos os termos em que se expressou e é novo o significado de sua ação. Nem "vida artística" nem "arte vital": regressar à origem da palavra, ao momento em que falar é sinônimo de criar. (...) Contudo, o surrealismo transpassa o significado de suas obras porque não é uma escola (ainda que constitua um grupo ou seita), mas uma poética (apesar de que um de seus postulados seja de ordem poética: o poder da inspiração), nem uma religião ou um partido político. O surrealismo é uma atitude do espírito humano. Talvez a mais antiga e constante, a mais poderosa e secreta. (Paz, 1980, p. 29-64)

Assim descreve André Breton (1994) a viagem que iniciou o surrealismo como prática coletiva:

Mas que caminhos escolher para partir? Caminhos materiais, era pouco provável; caminhos espirituais, não víamos quais pudessem ser. Seja como for, ocorreu-nos a ideia de combinar estas duas espécies de caminhos, e daí uma deambulação a quatro (Aragon, Morise, Vitrac e eu), empreendida a partir de Blois, cidade escolhida à sorte no mapa. Combinou-se que iríamos a pé, ao acaso: os únicos desvios voluntários permitidos serão os necessários para comer e dormir. A execução de um projeto tão singular depressa se revelou semeada de perigos. A viagem, prevista para cerca de dez dias, toma imediatamente feição inciática e vai ter que ser abreviada. A ausência de objetivo depressa nos abstrai da realidade, levantando sob os nossos passos fantasmas cada vez mais numerosos, cada vez mais inquietantes. (...) Exploração de nenhum modo decepcionante, no fim das contas, por exíguo que tenha sido o seu raio de ação, porque exploração nos confins da vida acordada e da vida de sonho, e desse modo a mais possível no estilo das nossas preocupações de então. (...) A verdade é que sanciona um modo de ver e sentir que teve sempre de se impor, refletir, precisar e formular em termos reivindicativos nos anos precedentes. Quando o Manifesto aparece, em 1924, tem atrás de si cinco anos de atividade experimental ininterrupta implicando um número e uma variedade apreciável de participantes. (Breton, 1994:85-87) 
No Brasil, para Antônio Candido (2004), a maior importância do surrealismo deu-se como forma de "abstração intelectual" pela maneira como as técnicas surrealistas foram assimiladas nos discursos de alguns de seus artistas: não como uma problemática vital ou uma concepção geral do pensamento e da literatura, mas sim como uma atitude do intelecto (Cândido, 2004, p. 22). Assim, se formos pensar nos termos de Candido, certas obras brasileiras, ou melhor, escritas no Brasil, possuem traços contingentes desta poética de crise construída por linguagens alimentadas pelo surrealismo.

Já para Floriano Martins (2001), a assimilação do surrealismo no caso brasileiro teve muito mais impacto do que somente certa influência intelectual. Inclusive, Martins sugere que o humanismo poético promovido pelo surrealismo teria contribuído para a "formação de uma rede possível de diálogos entre as culturas brasileiras e hispanoamericana" (Martins, 2001, p. 30), e apenas a leitura da obra poética de Aníbal Machado e Roberto Piva, já "nos daria uma dimensão exata da passagem - sempre em movimento - do Surrealismo por este país.”. Como descreve Martins:

Tomado por um humanismo radical, não raro confundido com perversão inconsequente, a aposta do brasileiro Roberto Piva foi a do rompimento com um positivismo exacerbado que tem causado profundos males ao desdobramento de toda uma cultura no Brasil. (...) Ao lado de Cláudio Willer e Sérgio Lima, Piva completa uma tríade essencial no desdobramento da aventura surrealista no Brasil, cuja essencialidade radicava na rejeição ao aspecto programático a que se costuma reduzir o Surrealismo. (...) Não cabe aqui discutir a já desgastada e nunca esclarecida questão: houve ou não Surrealismo no Brasil? (...) Rigorosamente se tratarmos do Surrealismo em um plano histórico ou retórico, excetuando instâncias chilenas e brasileiras, nada sobrará. Toda a modernidade, mesmo nos desdobramentos esteticistas ou cientificistas, sofreu o impacto de uma erupção onírica ou quando menos obteve a informação de um fervor animista, seja no ventre oculto da própria matriz cultural ou desperto por identificação com outras culturas (Martins, 2001: p.45-50).

Em 1924, a revista Estética (1924-1925), publicou o Manifesto pelos Direitos do Sonho, escrito por Sérgio Buarque de Holanda. Já em 1926, Mário Pedrosa tentou publicar juntamente com Antônio Bento e Lívio Xavier uma revista que abordasse exclusivamente o surrealismo. Durante período de guerra, em 1929, o surrealista francês Benjamin Perét desembarca no Brasil com uma carta de recomendação de Heitor VillaLobos. No mesmo ano, pouco antes de sua dissolução a Revista de Antropofagia assim saudou a chegada do poeta francês:

Está em São Paulo Benjamin Péret, grande nome do surrealismo parisiense. Não nos esqueçamos que o surrealismo é um dos melhores movimentos pré-antropofágicos. A liberação do homem como tal, através do ditado do inconsciente e das turbulentas manifestações pessoais, foi sem dúvida, um dos mais empolgantes espetáculos para qualquer coração de antropófago que nestes últimos anos tenha o desespero do civilizado. (...) Depois do surrealismo, só a antropofagia. Benjamin Perét (...) é um antropófago que merece cauins de cacique. (Revista de Antropofagia, segunda dentição, n.1. In: Diário de São Paulo, 17/03/1929.)

Benjamin Péret ficou no Brasil de 1929 a 1931, casou-se com a cantora lírica brasileira, Elsie Houston, e teve relações próximas com Mário Pedrosa e Antônio Bento, 
que chegaram a pensar em lançar um manifesto dentro do espírito inconformista surrealista, de valorização do irracional. Com o intento de pensar a arte mítica primitiva do Brasil, Perét chegou a organizar material para seu projeto de uma seleção de lendas e mitos indígenas, publicado postumamente como Anthologie des mythes, legendes et contes populaires d'Amériques (1960) ${ }^{\mathrm{ii}}$. No jornal paulistano Diário da Noite, de 25 de novembro de 1930 a 30 de janeiro de 1931, o poeta francês publicou uma série de treze artigos intitulados "Candomblé e makumba", descrevendo sua experiência com os ritos de candomblé como uma espécie de revelação poética sobre o transbordamento de uma "poesia primitiva e selvagem" dos "transes" dessa religião. Devido às suas associações com o Partido Comunista, foi expulso por Getúlio Vargas por decreto em 10 de dezembro de 1931. Ambos os livros O almirante negro de Benjamin Péret e Sinal de partida, de Mário Pedrosa (fruto de suas pesquisas surrealistas com Péret), foram apreendidos e destruídos pelos órgãos policiais do governo getulista. (Nazario Apud Guinsburg, 2008, p. 181).

Para Jorge Schartz (2008), Benjanim Péret possuía a motivação intelectual de "repetir o périplo surrealista europeu ao procurar na América e em Terra Brasilis uma espécie de matriz primitiva para traduzir o moderno" (p. 848). Segundo Schartz, Oswald de Andrade foi o responsável por popularizar o termo surrealismo na mídia impressa brasileira, que costumava chamar erroneamente o movimento francês de "supra" e/ou "super-realismo".

Em 1928, no Manifesto antropófago, Oswald de Andrade (2001) descreve os indígenas antropófagos como "surrealistas avant la lettre", pois com a língua tupi a estranheza do novo já estava aqui. Como defende Oswald: "nunca admitimos o nascimento da lógica entre nós (...) Já tínhamos a língua surrealista. Já tínhamos a Idade do Ouro. A magia e a vida.". Em sua obra, Oswald constrói paralelos com o primitivismo etnológico em voga entre os vanguardistas europeus, principalmente entre os surrealistas, de valorização dos componentes mágicos e instintivos da existência humana, descrevendo os tupis como portadores do "substrato inconsciente" de uma espécie de "religião natural" antropófaga como uma solução original de leitura da cultura brasileira. Se para André Breton “o olho existe em estado selvagem”, já Oswald de Andrade (2001) propõe "ver com os olhos livres" sua realidade cultural e a valorizar poeticamente os fatos etnográficos.

Para Benedito Nunes (1979, p. 11), Oswald de Andrade "com sua impaciência teórica" e "com sua particular avidez do novo e da novidade", foi "dos nossos modernistas, aquele que mais intimamente comungou com o espírito das vanguardas européias", tendo conseguido fundir "o sarcasmo europeu de Ubu Roi com a malícia brasileira de Macunaíma". Assim Nunes descreve a ligação entre certo elemento primitivo com a poética oswaldiana:

Foi através da óptica do primitivismo assim compreendido, que Oswald de Andrade interpretou e assimilou à sua própria obra as conquistas formais, as ousadias teóricas e o estilo de ação da prática da literatura e da arte novas que se acumulavam, às vésperas do advento do Surrealismo na ambiência intelectual de Paris agitada pelos últimos fogos 
cruzados das pequenas e irreverentes revistas adversas, a que ligaram seus nomes Cocteau e Radiguet, Picabia, Éluard e Tzara. Mário de Andrade acompanhava de São Paulo, lendo e anotando, os ecos dessa batalha campal, de que Oswald de Andrade assistia o coroamento, que foi o solene Te-deum surrealista celebrado pelo profeta Breton. (Nunes, 1979, p. 24-25)

Assim como Oswald adapta de certa forma o surrealismo ao caso brasileiro da linguagem tupi, Glauber Rocha (2004), algumas décadas depois, faz uma leitura singular da prática surrealista, defendendo a existência na América Latina de uma espécie de "surrealismo tropical", um "surrealismo concreto" que tenderia a combinar elementos baseados na irracionalidade com outros construtivistas, como descreve o cineasta:

Pablo Neruda já falava de um surrealismo concreto por este aspecto surreal, um fato dentro da realidade da América Latina e do Terceiro Mundo. Existe um surrealismo francês e outro que não o é. Entre Breton e Salvador Dalí tem um abismo. E o surrealismo é coisa latina. Lautréamont era uruguaio e o primeiro surrealista foi Cervantes. Neruda fala de surrealismo concreto. É o discurso das relações entre fome e misticismo. O nosso não é o surrealismo do sonho, mas da realidade. Buñuel é um surrealista, e seus filmes mexicanos são os primeiros filmes do tropicalismo e da antropofagia. A função histórica do surrealismo no mundo hispano-americano oprimido foi aquela de ser instrumento para o pensamento em direção de uma liberação anárquica, a única possível. Hoje utilizada dialeticamente, em sentido profundamente político, em direção do esclarecimento e da agitação. (Rocha, p. 152-153)

Por sua vez, Murilo Mendes relê o surrealismo a partir da idealização e adoção de um "surrealismo à brasileira". Em sua interpretação do surrealismo, "a vida em seus múltiplos movimentos e representações" deveria ser considerada como "muito mais surrealista que todos os surrealistas juntos." (Mendes apud Lima, 2010:37). Dessa maneira narra Mendes sua aproximação com um "surrealismo à brasileira":

Reconstituí também épocas distantes, a década de 1920, quando Ismael Nery, Mário Pedrosa, Aníbal Machado, eu e mais alguns poucos descobrimos no Rio o surrealismo. Para mim foi mesmo um coup de foudre. Claro que pude escapar da ortodoxia. Quem de resto conseguiria ser surrealista full time? Nem o próprio Breton. Abracei o surrealismo à moda brasileira, tomando dele o que mais me interessava: além de muitos capítulos de cartilha inconformista, a criação de uma atmosfera poética baseada na acoplagem de elementos díspares. (Mendes apud Guimarães, 1993: p.48)

Se o surrealismo ocupa um entrelugar na literatura brasileira, para Floriano Martins (2001, p. 31) tal fato deve-se a uma "suposta objetividade da arte" que acabou por sufocar todas as manifestações de cunhos irracionalistas na cultura brasileira. Se seguirmos essa linha de raciocínio, chegaremos a observar que comumente a "crítica oficial" brasileira mais adepta a um modernismo de cunho nacionalista tende por considerar o surrealismo apenas como uma prática de caráter programático, "reduzindoo à categoria leviana dos ismos, sem perceber a fundamental importância dos seus desdobramentos em diversas culturas". 
Sobre a ligação entre surrealismo e antropologia podemos citar Claude LéviStrauss (1990), que frequentou o mercado das pulgas parisiense junto com André Breton, viajou com o surrealista francês a bordo doe um navio rumo à Martinica, além de ter convivido com Max Ernst, Marcel Duchamp e Breton em Nova Iorque durante a Segunda Guerra. Assim, Lévi-Strauss narra seu diálogo com os surrealistas:

$\mathrm{Eu}$ admirava Breton, rendia homenagem ao seu olho infalível quando percorríamos os bricabraques: ele nunca errava quanto a um objeto, nunca hesitava em seu julgamento. (...) Em certo sentido, aceito esta aproximação. É verdade que os surrealistas e eu nos ligamos a uma mesma tradição intelectual que se origina na segunda metade do século XIX. Breton era apaixonado por Gustave Moreau, por todo aquele período do simbolismo e do neosimbolismo. Os surrealistas ficaram atentos ao irracional, procuraram explorá-lo do ponto de vista estético. É quase o mesmo material de que me sirvo, mas para tentar submetê-lo a análise, compreendê-lo, permanecendo sensível à sua beleza. Acrescentarei que reinava neste grupo um clima de exaltação intelectual, do qual me beneficiei muito. No contato com os surrealistas, meus gostos estéticos se enriqueceram e refinaram. Muitos objetos, que eu teria tido tendência a rejeitar como indignos, apareceram-me sob uma outra luz, graças a Breton e seus amigos. Foi com os surrealistas que eu aprendi a não temer as aproximações abruptas e imprevistas como as que Max Ernst usou nas suas colagens. (Strauss, 1990, p.48-50)

Já segundo aponta Fernanda Arêas Peixoto (1998, p. 79), os surrealistas “incorporam, por exemplo, o africano - efetivamente o 'outro' desvendado pela poesia francesa - em sua crítica cultural”. Nesse sentido, o etnólogo e poeta Michel Leiris, que participou em 1931 da missão cultural francesa de Dacar-Dijibuti (primeira expedição etnográfica e linguística para a África), é um "personagem emblemático" para se pensar a "íntima articulação entre etnologia e arte", por ser ele um poeta de feição surrealista que fez "opção pela etnologia, e isto não significa rupturas", ao contrário. No caso de Leiris, o interesse pela etnologia nasceu com o surrealismo, representando uma rebelião contra o racionalismo do ocidente, que se traduzirá na curiosidade pelos povos primitivos e pela mentalidade primitiva. Assim narra Peixoto a aproximação entre etnologia e surrealismo:

A aproximação da etnologia ao mundo das artes na França, dada principalmente pelo grupo surrealista, produz uma série de resultados interessantes, como por exemplo a revista Documents, editada por Georges Bataille a partir de 1929, que dedica um número inteiro à missão Dakar-Djibouti; ou o catálogo da exposição Les Arts Anciens de l'Amérique Disparue, organizada por George Henri-Rivère em 1928, para o qual Bataille escreve "L'Amérique Disparue". A posição anticolonialista dos surrealistas mobiliza o interesse pelos povos colonizados e leva vários de seus partidários a escreverem textos de caráter etnológico. Mas tal posição, longe de significar uma bandeira política - que outros também levantaram -, tem um sentido mais profundo no interior da "filosofia" surrealista. Ferozes e irreverentes críticos do ponto de vista antropocêntrico, os membros do grupo compartilham a convicção acerca da necessidade das fronteiras do humano. Nesse sentido, o homem não poderia ser mais pensado sem os seus "outros", sem os seus "duplos": os animais, as figuras monstruosas, os primitivos (Peixoto, 1998, p. 84-85). 
De maneira singular, James Clifford (1998, p. 149-151) propõe uma aproximação da etnografia com as colagens surrealistas, de modo a trazer ao texto etnográfico "elementos que continuamente proclamam sua condição estrangeira ao contexto da apresentação". Assim, a ideia da etnografia como collage se constrói a partir de montagens que, lidando com a justaposição de valores culturais, também visariam embaralhar e contestar a realidade racional, "compondo e decompondo as hierarquias e relações 'naturais' da cultura". Esta dimensão etnográfica da prática surrealista conceberia o elemento primitivo como parte de sua poética e conteria "outras vozes além da do etnógrafo, assim como exemplos de evidências 'encontradas', dados não totalmente integrados na interpretação organizadora do trabalho", como problematiza Clifford:

\begin{abstract}
Deve-se lembrar que o surrealismo tinha sido um fenômeno genuinamente internacional, com manifestações em cada continente. Ele forjou a articulação menos das diferenças culturais do que das diferenças humanas. $\mathrm{O}$ mesmo pode ser dito em geral da etnografia francesa. (...) Apresentando esquematicamente o contraste, podemos dizer que o humanismo antropológico parte do diferente e o faz - através de nomeá-lo, de classificá-lo, de descrevê-lo e de interpretá-lo - compreensível. Ele o familiariza. Uma prática etnográfica surrealista, ao contrário, ataca o familiar, provocando a irrupção da alteridade - o inesperado. Cada uma dessas atitudes pressupõe outra; ambas são elementos no interior de um complexo processo que gera significados culturais, definições de nós mesmos e do outro. (...) O momento surrealista em etnografia é aquele no qual a possibilidade de comparação existe numa tensão não mediada com a mera incongruência. Este momento é repetidamente produzido e suavizado no processo da compreensão etnográfica. (...) Pensar o surrealismo como etnografia é questionar o papel central do 'artista' criativo (...) O surrealismo unido à etnografia resgata sua antiga vocação de política cultural crítica. (Clifford, 1998, p. 135-169).
\end{abstract}

Se para Louis Aragon (Aragon apud Vasconcelos, 1977), toda poesia é "surrealista" em seu movimento de busca por uma objetividade análoga à do sonho, Octavio Paz (1996, p. 224) ressalta que a poética surrealista não pode ser interpretada dentro de um viés de uma escola poética, mas sim através de um enfoque que considere seu caráter revolucionário; "revolucionário porque é uma volta ao princípio do princípio." Como um ato que busca uma libertação total através de uma "via de reconquista da linguagem inocente e renovação do pacto primordial". Assim, o processo de criação surrealista é exposto como uma prática que se reafirma por estar sempre em processo, como um ato apaixonado, uma ação de vida ou um estado de espírito que não pode ser definido exatamente como um movimento programático de vanguarda histórica, passível de ser classificado através do sufixo “ismo". Interpretação parecida possui Marcel Duchamp (2008), ao afirmar não ser o surrealismo uma escola ou movimento fechado e acabado. Duchamp define o surrealismo como um "estado de espírito", um "existencialismo", uma "questão de comportamento". Nesse sentido, para Duchamp, a atitude do artista surrealista deveria contar mais do que sua obra.

$\mathrm{O}$ que este artigo buscou probolematizar foi a interlocução entre filosofia e literatura, a partir do surrealismo como uma prática poética-filosófica que se expande 
por diversas áeras extra-literárias. Creio que o tema é de extrema importância não somente pelo seu ineditismo, mas também por remeter a certa interpretação de um passado cultural recente que teve seu impacto também no cenario brasileiro, e ainda está longe de ser esgotado. Como apontava o poeta argentino Enrique Molina (Molina apud Martins, 2001, p. 18), o surrealismo pode ser descrito, de algum modo, como a "encarnação de um mito da poesia que perdura e dá um sentido muito especial à tarefa e ao conceito do poeta". Todo poeta seria surrealista em seu sentido mais amplo, pelo fato de o surrealismo não ser uma "escola literária", mas sim um "humanismo poético, em que no centro está o homem - não a divindade - projetado ao absoluto e ao infinito, com todos os poderes implícitos na condição humana". Assim completa Molina: "Eu creio que nenhum poeta pode deixar de querer o Surrealismo". 
i Para Steven Webster (1990) as releituras de Walter Benjamin sobre Baudelaire, as multidões parisienses e o surrealismo estão intrincadas: "I point out the continuity that Benjamin was developing in the terms of "modernism" between Baudelaire's understanding of the Parisian crowds and his own critique of surrealism." (p.296) Com uma prática política de transgressão, Benjamin retrata Baudelaire como um refugiado urbano, com sua exploração ambígua da metrópole improvisada nos seus passos precários que vão se reinventando ao passar por cada rua. Sua construção poética é construída a partir da tensão entre a vida e os livros.

ii Para o historiador Clóvis Moura (apud Ponge, 1999:72), este conjunto de artigos de Benjamin Péret, constitui "um marco significativo dos estudos afro-brasileiros, levando-se em consideração, inclusive, o seu pioneirismo, pois ele precede Gilberto Freyre, Arthur Ramos, Édson Carneiro e os demais africanistas brasileiros.” No Brasil, os escritos de Péret foram reunidos no livro Quilombo dos Palmares (2002), organizado por Robert Ponge.

\section{Referências bibliográficas:}

ANDRADE, Oswald de. A utopia antropofágica / Oswald de Andrade. $3^{\text {a }}$ Ed. São Paulo: Globo: 2001.

BALAKIAN, Anna. Surrealism. The road to absolute. Clarke, Irwin \& Company Limited, Toronto and Vancouver, 1970.

BENJAMIN, Walter. "Rua de mão única". In Walter Benjamin. Obras escolhidas. (Volume II). São Paulo, Editora Brasiliense, 1987.

BRETON, André. Manifestos do Surrealismo / André Breton; tradução: Sergio Pachá. Rio de Janeiro: Nau Editora, 2001.

- Entrevistas (tradução Ernesto Sampaio). Lisboa, Edições Salamandra: 1994: p.110. (Título original: Entrétiens André Breton. Paris, Editions Gallimard: 1952).

CABANNE, Pierre. Marcel Duchamp: engenheiro do tempo perdido. São Paulo: Perspectiva, 2008.

CANDIDO, Antonio. "Surrealismo no Brasil". In: Brigada ligeira. Rio de Janeiro: Ouro sobre Azul, 2004.

CLIFFORD, James. A experiência etnográfica: Antropologia e Literatura no século XX/ James Clifford; organizado por José Reginaldo Gonçalves. Rio de Janeiro: Editora UFRJ, 1998.

COMPAGnON, Antoigne. Os Cinco Paradoxos da Modernidade. Belo Horizonte: Editora UFMG, 1996.

CORTÁZAR, Júlio. “Surrealismo”. In: Obra crítica. Rio de Janeiro: Civilização Brasileira, 1998.

GUIMARÃES, Júlio César Castañon. Territórios/ conjunções: poesia e prosa críticas de Murilo Mendes. Rio de Janeiro: Imago Ed., 1993.

GUINSBURG. J.; LEIRNER, SHEILA. (org). O Surrealismo. São Paulo: Perspectiva, 2008.

LÉVI-STRAUSS, Claude. De perto e de longe. Rio de Janeiro, Nova Fronteira, 1990.

LIMA, Jorge de. A Pintura em Pânico. Fotomontagens. Jorge de Lima. Catálogo da exposição realizada entre 15 de março e 02 de maio de 2010 - CAIXA Cultural Rio de Janeiro - Galeria 1. 
MARTINS, Floriano. O começo da busca: O surrealismo na poesia da América Latina. São Paulo: Escrituras Editora, 2001.

NUNES, Benedito. "Antropofagia ao alcance de todos". In: ANDRADE, Oswald de. A utopia antropofágica / Oswald de Andrade. $3^{\text {a }}$ Ed. São Paulo: Globo: 2001.

. Oswald Canibal. São Paulo: Editora Perspectiva, 1979.

PAZ, Octavio. Os Filhos do Barro: do romantismo à vanguarda. Rio de Janeiro: Nova Fronteira, 1984.

La Busqueda Del Comienzo (Escritos sobre el surrealismo). Introduccion: Diego Martinez Torron. Madrid, Editorial Fundamentos, 1980.

.André Breton ou a busca do início". In: Signos em rotação. Trad. Sebastião Uchoa Leite. São Paulo: Perspectiva, 1996.

PEDROSA, Mário. Modernidade cá e lá: textos escolhidos IV / Mário Pedrosa; Otília Arantes (org). - São Paulo: Editora da Universidade de São Paulo, 2000.

PEIXOTO, Fernanda Arêas. Lévi-Strauss no Brasil: a formação do etnólogo. In: Mana, vol.4, n.1. Rio de Janeiro, 1998: 79-107.

PÉRET, Benjamin. Anthologie des mythes, legendes et contes populaires d'Amériques. Paris, Albin Michel, 1960. $\overline{17 / 03 / 1929 .}$

. "Perét". In: Revista de Antropofagia, segunda dentição, n.1. In: Diário de São Paulo,

PIVA, Roberto. Roberto Piva. Rio de Janeiro: Beco do azougue, 2009.

POGGLIOLI, Renato. The Teory of the Avant-Garde. The Belknap Press of Harvard University Press. Cambridge, Massachusetts: 1968.

PONGE, Robert. (org) Surrealismo e novo mundo. Porto Alegre: Ed. Universidade. UFRGS, 1999.

ROCHA, Glauber. "Tropicalismo, antropofagia, mito, ideograma” (1969). In: Revolução do

Cinema Novo. São Paulo: Cosac Naify, 2004.

SÁBATO, Ernesto. O escritor e seus fantasmas. Rio de Janeiro: Francisco Alves, 1982.

VASCONCELOS, Mário Cesariny de. Textos de afirmação de combate do movimento surrealista mundial. Lisboa: Perspectiva e realidades, 1977.

WEBSTER, Steven. "The historical materialist critique of Surrealism and postmodernist Ethnography." In: . Modernist Anthropology; from field to text. Edited and with an Introduction by Marc Mangaro. Princeton University Press, 1990. 